\title{
Cyanide inhibits respiration yet stimulates aerobic growth of Zymomonas mobilis
}

\author{
Uldis Kalnenieks, ${ }^{1}$ Nina Galinina, ${ }^{1}$ Malda M. Toma ${ }^{1}$ and Robert K. Poole ${ }^{2}$
}

1 Institute of Microbiology and Biotechnology, University of Latvia, Kronvalda boulv. 4, Riga LV-1586, Latvia

2 Krebs Institute for Biomolecular Research, Department of Molecular Biology and Biotechnology, The University of Sheffield, Firth Court, Western Bank, S10 2TN Sheffield, UK
Author for correspondence: Robert K. Poole. Tel: +44 114222 4447. Fax: +44 1142728697. e-mail: r.poole@sheffield.ac.uk

\begin{abstract}
Potassium cyanide at submillimolar concentrations (20-500 $\mu \mathrm{M})$ inhibited the high respiration rates of aerobic cultures of Zymomonas mobilis but, remarkably, stimulated culture growth. In batch culture, after an extended lag phase, exponential growth persisted longer, resulting in higher biomass densities. In aerobic chemostat cultures, elevated biomass concentration was observed in the presence of cyanide. This growth stimulation effect is attributed to decreased production of the inhibitory metabolite acetaldehyde at lowered respiration rates, when more reducing equivalents are channelled to alcohol dehydrogenase. Growth in the presence of cyanide did not alter the membrane cytochrome content. In non-growing cyanide-preincubated cells, with ethanol as the respiratory substrate, cyanide increased ATP levels; in such cells, a large part of the cyanide-sensitive respiration was inhibited within a few seconds after ethanol addition, while inhibition of the rest of respiration took several minutes. The more cyanide-sensitive respiration was apparently energy-nongenerating, and was absent in membrane preparations. Pelleting of membranes from cell-free extracts produced 'soluble' fractions in which a $b$ type haem was detectable by reduced minus oxidized difference spectroscopy. The function of the $Z$. mobilis respiratory chain in cell growth and respiratory protection, and the possible physiological role of aerobic generation of inhibitory metabolites, are discussed.
\end{abstract}

Keywords: Zymomonas mobilis, cyanide sensitivity, respiratory protection, cytochromes, acetaldehyde

\section{INTRODUCTION}

The Gram-negative, aerotolerant, ethanol-producing bacterium Zymomonas mobilis possesses a branched respiratory chain (Kalnenieks et al., 1998) with an oxidative phosphorylation activity (Kalnenieks et al., 1993). However, the overall physiological role of respiration in Z. mobilis is still obscure. Z. mobilis rapidly catabolizes available sugar to ethanol, while concomitantly only a small fraction of carbon substrate is converted into biomass. This growth pattern of $Z$. mobilis is known as energetically uncoupled growth (Belaich \& Senez, 1965; Jones \& Doelle, 1991). Respiration in Z. mobilis clearly does not serve as an energy source for aerobic biomass growth in the way respiration does in most facultatively anaerobic and aerobic bacteria (Bringer et al., 1984; Pankova et al., 1985), as judged from the low aerobic biomass yields. The highest reported biomass yield values for Z. mobilis are slightly above $20 \mathrm{~g}$ dry biomass per mol glucose, obtained for aerobic chemostat culture at high flow rate, low glucose concentration and efficient ventilation, ensuring removal of volatile inhibitory metabolic byproducts (Zikmanis et al., 1997). Besides, the fermentative catabolism of $Z$. mobilis is well balanced, yielding $2 \mathrm{~mol}$ ethanol per mol of catabolized glucose via the Entner-Doudoroff path-

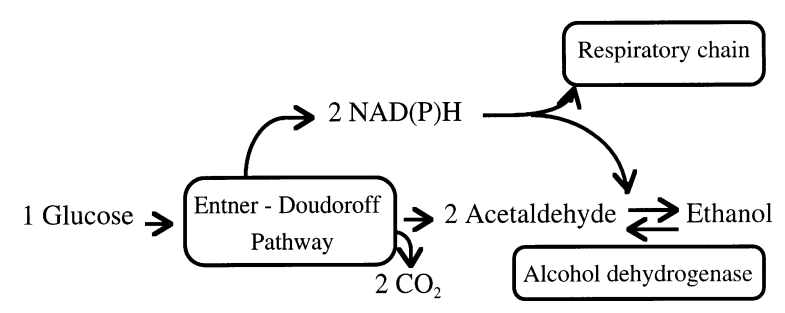

Fig. 1. Competition for reducing equivalents between the respiratory chain and alcohol dehydrogenase during aerobic glucose catabolism in Z. mobilis. Respiratory consumption of $\mathrm{NAD}(\mathrm{P}) \mathrm{H}$ limits reduction of acetaldehyde to ethanol. Conversely, inhibition of respiration causes less acetaldehyde to accumulate. 
way (Viikari, 1988). Z. mobilis lacks any further pathways, like the Krebs cycle (Bringer-Meyer \& Sahm, 1989), for supplying additional reducing equivalents to the respiratory chain. In aerobic culture, the respiratory chain has to compete for $\mathrm{NAD}(\mathrm{P}) \mathrm{H}$ with the alcohol dehydrogenase reaction (Fig. 1), thus causing accumulation of the toxic metabolic precursor of ethanol, acetaldehyde (Bringer-Meyer \& Sahm, 1988; Ishikawa et al., 1990; Viikari, 1988). Acetaldehyde, as well as other metabolites accumulating in aerobic culture (like dihydroxyacetone and acetate), have been described as growth inhibitors of Z. mobilis (Bringer et al., 1984; Ishikawa et al., 1990; Viikari, 1988; Wecker \& Zall, 1987).

Nevertheless, aerated Z. mobilis cells respire at considerable rates (Kalnenieks et al., 1995; Pankova et al., 1988), and oxic conditions appear to affect the structure and function of the respiratory chain. Under aerobic conditions, an increase of the cytochrome $\alpha$-peak in the reduced minus oxidized difference spectra was reported (Kalnenieks et al., 1996). Moreover, in anaerobically grown cells, oxidative phosphorylation activity is linked solely to 'site I' (NADH dehydrogenase), while in aerobically grown cells it shifts to the cytochrome region of the respiratory chain (Kalnenieks et al., 1995, 1996), and the energy-nongenerating $\mathrm{NADH}$ dehydrogenase of type II prevails (Kalnenieks et al., 1996; Kim et al., 1995).

In order to gain more understanding of the role of respiration in aerobically growing $Z$. mobilis, we examined aerobic growth under conditions in which the respiration of cells is inhibited by submillimolar cyanide concentrations. Cyanide was chosen because it is one of the few water-soluble inhibitors able to cross the membranes of Z. mobilis, thus allowing it to be used in growing, intact cells. Furthermore, additional information might come from the fact that cyanide-sensitive and -resistant branches of bacterial respiratory chains often differ with respect to their energy-conserving efficiency (Poole, 2000; Poole \& Cook, 2000). Here we report the effects of cyanide on culture growth, respiration, acetaldehyde production and ethanol yield, aerobic ATP synthesis and cytochrome content in $Z$. mobilis.

\section{METHODS}

Bacterial strain and batch growth conditions. Anaerobic overnight cultures of Z. mobilis strain ATCC 29191 were used for inoculation, and aerobic cultivations were carried out on a shaker ('Infors') at 200 r.p.m. and $30^{\circ} \mathrm{C}$ in 0.51 unbaffled flasks containing $50 \mathrm{ml}$ culture. Cultures referred to as 'anaerobic' were grown under oxygen-limited conditions in 11 flasks containing 11 culture incubated at the same temperature without shaking. The growth medium contained glucose $\left(50 \mathrm{~g} \mathrm{l}^{-1}\right)$, Difco yeast extract $\left(5 \mathrm{~g} \mathrm{l}^{-1}\right)$ and mineral salts (Kalnenieks et al., 1993). During batch growth, the $\mathrm{pH}$ of the medium changed from $5 \cdot 6-5 \cdot 7$ at the beginning to about $4 \cdot 5-4 \cdot 8$ at the end of cultivation. For studies of respiration and ATP synthesis in non-growing bacteria, aerobically growing exponential-phase cells were harvested by centrifugation, washed and resuspended in $50 \mathrm{mM}$ potassium phosphate buffer (pH 6.9), supplemented with $5 \mathrm{mM}$ magnesium sulfate, to a cell concentration of about $3.5 \mathrm{mg}$ (dry wt) $\mathrm{ml}^{-1}$.

Continuous cultivation. Continuous cultivation was carried out in a Labfors fermenter ('Infors'), $800 \mathrm{ml}$ working volume, at $30^{\circ} \mathrm{C}$, with aeration at $11 \mathrm{~min}^{-1}$, and stirring at 410 r.p.m. The growth medium was the same as for batch cultivations, except that the glucose concentration was $25 \mathrm{~g} \mathrm{l}^{-1}$. The flow rate $(D)$ was set at $0.23 \mathrm{~h}^{-1}$. $\mathrm{pH}$ was maintained at 6.0 by automated additions of a $10 \%(\mathrm{w} / \mathrm{v}) \mathrm{KOH}$ solution. Potassium cyanide solution $(1 \mathrm{mM})$ was pumped into the culture separately from the growth medium (because cyanide is unstable in slightly acidic medium) at $10 \%$ of the medium flow rate (approx. $20 \mathrm{ml} \mathrm{h}^{-1}$ ), thus resulting in a continuous feed of $100 \mu \mathrm{M}$ cyanide. Fresh cyanide stock solution was prepared every $4 \mathrm{~h}$. Five fermenter working volumes were exchanged during transition between two steady states.

Preparation of cytoplasmic membranes. Cells were disrupted by sonication (with a Soniprep ultrasonic processor) using seven periods of $1 \mathrm{~min}$ duration, each with $1 \mathrm{~min}$ intervals for cooling, if not stated otherwise. Subsequent removal of unbroken cells and pelleting of membranes by ultracentrifugation was done as described previously (Kalnenieks et al., 1993).

Cytochrome spectroscopy. Room-temperature reduced minus oxidized difference spectra were taken using $1 \mathrm{ml}$ samples of membrane suspension with small amounts of solid sodium dithionite as reductant and potassium ferricyanide as oxidant. Alternatively, no oxidant was added; these samples are named 'as prepared'. Spectra were recorded using a custom-built SDB-4 dual-wavelength scanning spectrophotometer, as described previously (Kalnenieks et al., 1998; Eaves et al., 1998).

Analytical methods. Glucose was determined with a Sigma glucose oxidase kit, and ethanol with a Sigma alcohol dehydrogenase kit, following the manufacturer's instructions. Oxygen consumption was measured at regular time intervals in $2 \mathrm{ml}$ culture samples, which were rapidly transferred from the shaken flasks directly into a Clark electrode chamber (Rank Bros.) and their respiration monitored without external substrate addition. For non-growing cells, a small amount of suspension was added to buffer in the electrode chamber, to give about a 50-fold dilution. Potassium cyanide was added to the desired concentration and, after 5-10 min incubation, respiration was started by addition of ethanol at $5 \mathrm{~g} \mathrm{l}^{-1}$ (final concentration). Acetaldehyde concentration was determined using the alcohol dehydrogenase reaction and monitoring absorbance change at $340 \mathrm{~nm}$ (Stanley et al., 1997). ATP in samples was assayed by the luciferin-luciferase method, as described previously (Kalnenieks et al., 1995). Protein concentration was determined according to Markwell et al. (1978). Cell concentration was determined as optical density at $550 \mathrm{~nm}$ in cells of $1 \mathrm{~cm}$ pathlength in a Jenway 6100 spectrophotometer, after appropriate dilution to maintain apparent absorbance readings below about $0 \cdot 7$. Dry cell mass of the suspensions was calculated by reference to a calibration curve. All experiments described are typical of several replicates. Standard errors of means are given as error bars in the figures.

\section{RESULTS}

\section{Aerobic batch growth, respiration and cytochrome content in the presence of cyanide}

The growth curves of $Z$. mobilis in aerobic batch culture in the presence of various potassium cyanide concentrations are shown in Fig. 2. Remarkably, cyanide 


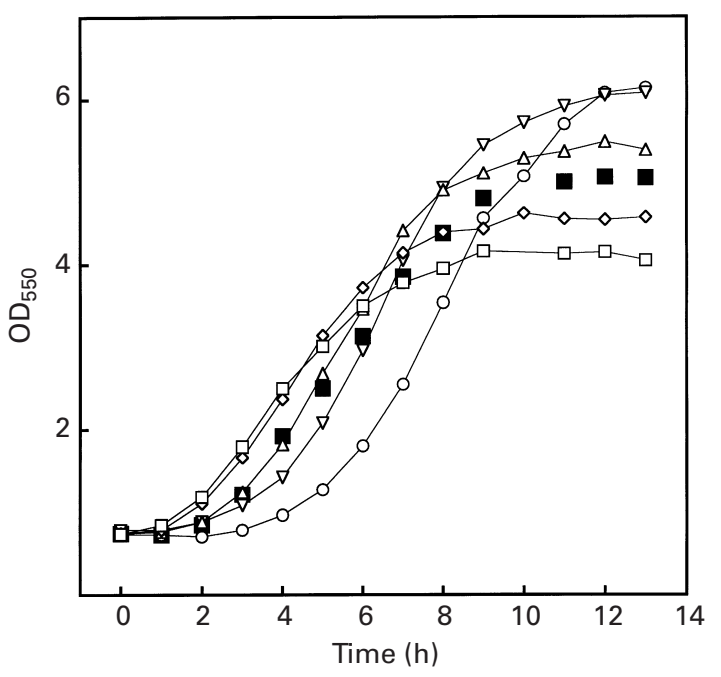

Fig. 2. Aerobic growth in the presence of various cyanide concentrations. Cyanide was added immediately after inoculation, to final concentrations $(\mu \mathrm{M})$ of: $0(\square), 20(\diamond), 100$ $(\triangle), 200(\nabla)$, and $500(\bigcirc)$. Anaerobic cultivation was performed in parallel without cyanide addition ( $\square$ ).

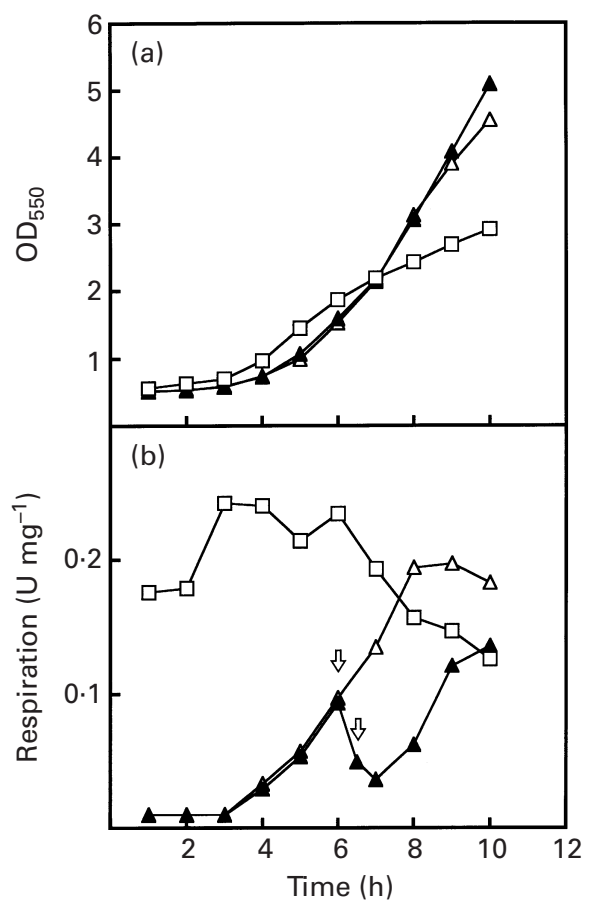

Fig. 3. Growth (a) and specific rate of oxygen consumption (b) of two aerobic batch cultures with $100 \mu \mathrm{M}$ cyanide $(\triangle, \boldsymbol{\Delta})$, and a control without cyanide addition $(\square)$. Arrows indicate further additions of cyanide to one of the cyanide-treated cultures $(\boldsymbol{A})$, each of which increased the total added concentration by $20 \mu \mathrm{M}$.

strongly stimulated aerobic growth. Aerobically growing cultures without added cyanide entered stationary phase at cell concentrations lower than those reached in anaerobic cultures (Figs 2 and 5c). At only $20 \mu \mathrm{M}$, cyanide showed a stimulating effect. With $100 \mu \mathrm{M}$ or higher cyanide concentrations, aerobic growth resulted in biomass densities exceeding those of both aerobic and anaerobic control cultures (Fig. 2). However, cyanide, particularly at higher concentrations caused an extension of lag phase.

Specific rates of respiration, expressed as international units $\left(\mu \mathrm{mol} \mathrm{O}_{2} \mathrm{~min}^{-1}\right)$ per mg dry weight, for the control culture and two batch cultures with $100 \mu \mathrm{M}$ cyanide are shown in Fig. 3(b). The control culture displayed a comparatively high specific oxygen uptake rate, which increased during exponential growth and gradually dropped as the growth slowed. Parallel growth measurements (Fig. 3a) confirmed a linear growth pattern, which terminated at a low $\mathrm{OD}_{550}$ value. In marked contrast, cultures supplemented with $100 \mu \mathrm{M}$ cyanide exhibited no detectable respiration during the first $3 \mathrm{~h}$ of cultivation (Fig. 3b). With $50 \mu \mathrm{M}$ cyanide the effect was similar (not shown). The inhibition caused by cyanide was transient: after $3 \mathrm{~h}$, respiration rates in the cyanidetreated cultures started to rise. To determine whether this respiration was due to induction of a cyanideinsensitive electron transport pathway, common in bacteria (Ashcroft \& Haddock, 1975; Kita et al., 1984; Knowles, 1976), the emerging respiratory activity was titrated with two sequential additions of $20 \mu \mathrm{M}$ cyanide (Fig. 3b). The inhibition following this treatment suggests that, at least in part, cyanide sensitivity was retained. We speculate that during the first few hours of $Z$. mobilis growth, some cyanide might be decomposed. Partial inhibition of the emerging respiration by these small cyanide increments slightly but reproducibly stimulated the growth of the respective cyanide-treated culture further (Fig. 3a). Therefore, in the following batch experiments, in addition to the initial cyanide treatment, small amounts of cyanide were also added during the course of culture growth.

Fig. 4 shows the reduced minus oxidized difference spectra of membrane preparations obtained from anaerobic and aerobic control cultures, and from an aerobic culture grown in the presence of cyanide. Unlike Escherichia coli, in which significant induction of cytochrome $b d$ occurs when cells are grown aerobically in the presence of cyanide (Ashcroft \& Haddock, 1975), there were no obvious differences in the membrane cytochrome content between the control and the cyanide-treated aerobic cultures of $Z$. mobilis. The spectral feature at $629-631 \mathrm{~nm}$, attributed to cytochrome $d$, was of approximately the same magnitude in all three samples. The $\alpha$-peak of the $b$-type cytochromes at $557-558 \mathrm{~nm}$ for the aerobic control culture (Fig. 4, B) was about double the height of the $\alpha$-peak in membranes of the anaerobic control (Fig. 4, C). The aerationdependent increase of the $\alpha$-peak is in agreement with our earlier findings in reduced minus oxidized spectra of whole cells (Kalnenieks et al., 1996). However, the $\alpha$ peak in the membranes of the cyanide-treated cells (Fig. 4, A) was similar in magnitude to that of the aerobic control (Fig. 4, B). The lack of distinct cyanide-induced 


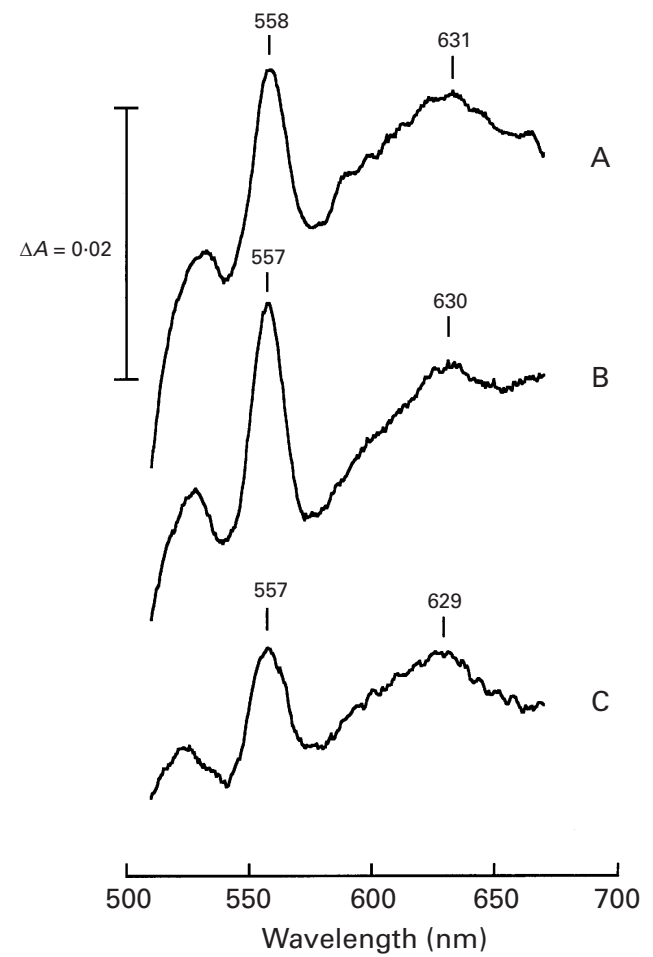

Fig. 4. Reduced minus oxidized difference spectra at room temperature of cytochromes in membrane preparations obtained from cells grown: aerobically in the presence of $100 \mu \mathrm{M}$ cyanide (A), aerobically without addition of cyanide (B), anaerobically without addition of cyanide (C). Sodium dithionite was used as the reductant and potassium ferricyanide as the oxidant. Protein concentration in all samples was $6.7 \mathrm{mg} \mathrm{ml}^{-1}$. Similar results were obtained in replicate scans.

features in the Z. mobilis cytochrome spectra supports the observation that increased respiration a few hours after cyanide addition is not unusually cyanide-resistant, and suggests that the growth stimulation does not stem from any marked cyanide-induced changes of the membrane cytochrome content.

\section{Glucose consumption, acetaldehyde generation and biomass yield}

It is well established (Viikari, 1988) that the growth of $Z$. mobilis in anaerobic batch culture persists until all the sugar in the medium is utilized (see Fig. 5b). However, under conditions of vigorous aeration, growth and glucose consumption become inhibited soon after the beginning of exponential phase. In the aerobic experiments shown in Fig. 5, growth of the control culture stopped long before glucose in the medium was exhausted, and even after $25 \mathrm{~h}$ of cultivation, well into stationary phase, the growth medium still contained almost $20 \mathrm{~g}$ glucose $\mathrm{l}^{-1}$. Addition of $100 \mu \mathrm{M}$ cyanide at the beginning of cultivation and subsequently as additions, each giving an additional $20 \mu \mathrm{M}$ (final concentration) (Fig. 5c, marked by the filled arrows),

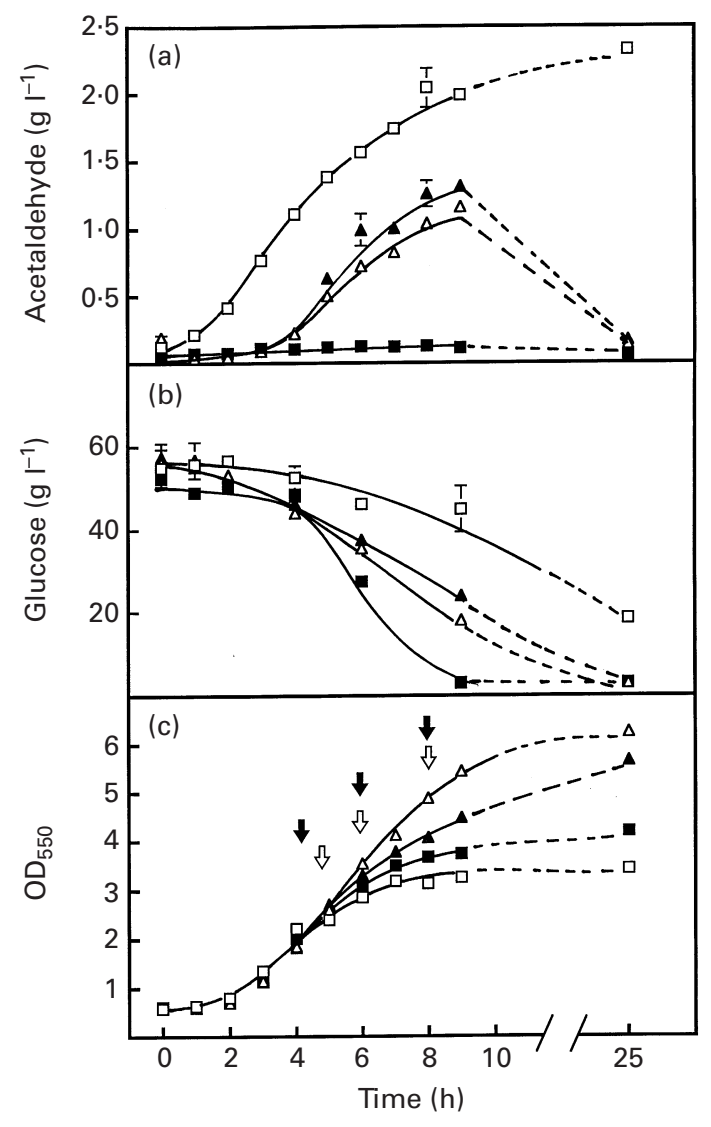

Fig. 5. Effects of cyanide on acetaldehyde production (a), glucose consumption (b), and culture growth (c). $\square$, Aerobically growing control culture; $\mathbf{\square}$, anaerobically growing control culture; $\triangle, \boldsymbol{\Delta}$, aerobically growing cultures with $100 \mu \mathrm{M}$ cyanide, supplemented with small amounts of cyanide (where indicated by the filled arrows), each raising the cyanide concentration by $20 \mu \mathrm{M}$. One of the cyanide-treated cultures (A) received several small increments of acetaldehyde (where indicated by the empty arrows), each raising the acetaldehyde concentration by about $0.1 \mathrm{~g} \mathrm{I}^{-1}$. All analyses were performed in triplicate: the bars in (a) and (b) represent SEM (shown only where larger than the symbols for the data points).

substantially accelerated glucose consumption, although not to the level of the anaerobic culture.

As anticipated by the scheme in Fig. 1, the high respiration rate of the aerobic control was accompanied by abundant accumulation of acetaldehyde in the culture medium (Fig. 5a). The concentration of acetaldehyde reached more than $2 \mathrm{~g} \mathrm{l}^{-1}$, which is known to cause severe inhibition of growth and metabolism in $Z$. mobilis (Wecker \& Zall, 1987). However, in a cyanidetreated culture with partially inhibited respiration, the generation of acetaldehyde started later and proceeded more slowly, so that during the cultivation acetaldehyde did not reach levels as high as those of the aerobic control (Fig. 5a). Growth of Z. mobilis was sensitive to small changes in acetaldehyde concentration: addition of several small increments of acetaldehyde to one of the cyanide-treated cultures (Fig. 5c, marked by the empty 
Table 1. Effect of cyanide on an aerobic chemostat culture

The values are means of 9-17 measurements in each steady state. Fluctuations in metabolite concentrations, $\mathrm{pO}_{2}$ and yields were within $10 \%$ of the mean values shown.

\begin{tabular}{|lcc|}
\hline Parameter & \multicolumn{2}{c|}{ Steady state } \\
\cline { 2 - 3 } & With $\mathbf{1 0 0} \boldsymbol{\mu M}$ cyanide & Control \\
\hline $\mathrm{pO}_{2}(\%$ saturation $)$ & 37 & 41 \\
$\mathrm{X}$ (g dry wt l $\left.{ }^{-1}\right)$ & 0.58 & $0 \cdot 43$ \\
{$\left[\right.$ Acetaldehyde $\left(\mathrm{g} \mathrm{l}^{-1}\right)$} & $0 \cdot 46$ & $0 \cdot 35$ \\
$Q_{\text {glucose }}\left(\mathrm{mmol} \mathrm{g}^{-1} \mathrm{~h}^{-1}\right)$ & $25 \cdot 8$ & $46 \cdot 0$ \\
$Y_{\mathrm{X} / \mathrm{s}}\left({\left.\mathrm{g} \mathrm{dry} \mathrm{wt} \mathrm{mol}^{-1}\right)}\right.$ & $8 \cdot 9$ & $5 \cdot 0$ \\
$Y_{\mathrm{EtOH}}\left(\mathrm{g} \mathrm{g}^{-1}\right)$ & $0 \cdot 28$ & $0 \cdot 13$ \\
\hline
\end{tabular}

arrows) caused slight inhibition of growth relative to the culture that received only cyanide. Thus, stimulation of growth by cyanide was largely due to inhibition of acetaldehyde generation in the aerated cultures. Along with inhibition of acetaldehyde generation, cyanide increased ethanol yield $\left(Y_{\mathrm{EtOH}}\right)$ during exponential growth phase: for the control culture in Fig. 5 between the first and sixth hour of cultivation $Y_{\mathrm{EtOH}}$ was $0.26 \mathrm{~g}$ ethanol per g consumed glucose, while in the presence of $100 \mu \mathrm{M}$ cyanide it reached $0.42 \mathrm{~g}$ per $\mathrm{g}$ glucose.

In exponential phase, molar growth yields $\left(Y_{\mathrm{x} / \mathrm{s}}\right)$, estimated from the data in Fig. 5 (between the first and sixth hour of growth) were low and did not correlate with the biomass densities reached in the stationary phase. Under our experimental conditions, in all cases the growth yields were below $10 \mathrm{~g}$ dry biomass per mol consumed glucose. The aerobic control culture showed the highest yield, $7 \cdot 9 \mathrm{~g}$ dry wt per mol glucose. For the anaerobic control, the yield was $4.2 \mathrm{~g}$ dry wt per mol glucose, while the cyanide-treated aerobic cultures showed intermediate values, around $5 \cdot 1-5 \cdot 2 \mathrm{~g}$ dry wt per mol glucose.

\section{Cyanide effect on aerobic growth and product formation in continuous culture}

The parameters of chemostat cultivation with continuous feeding of $100 \mu \mathrm{M}$ cyanide are presented in Table 1. Continuous culture in a fermenter offered two advantages over batch cultivation: (1) provision of a constant cyanide concentration and maintenance of growth parameters for prolonged periods; (2) vigorous gassing of the culture, efficiently removing acetaldehyde. Therefore, it was possible to study cyanide effects on an aerobic culture, which generated, but did not accumulate, volatile inhibitory by-products.

As in batch cultures, cyanide significantly stimulated biomass growth (Table 1). Not only the steady-state biomass concentration $(X)$, but also the biomass yield $\left(Y_{\mathrm{x} / \mathrm{s}}\right)$ was elevated. As a result of ventilation, for both steady states, acetaldehyde concentrations did not exceed $0.5 \mathrm{~g} \mathrm{l}^{-1}$. Dissolved $\mathrm{O}_{2}$ concentration was similar under both conditions. Yet, it followed from redox balance considerations that the specific rates of acetaldehyde generation must have been lower in the presence of cyanide. This was because (Table 1): (1) ethanol yield in the steady state with cyanide had more than doubled as a consequence of partial inhibition of respiration; (2) with cyanide, the specific rate of glucose consumption was lower. The latter was probably due to some inhibitory effect of cyanide on glucose uptake and/or catabolism; this needs further investigation. Clearly, the inhibition of glucose consumption caused by acetaldehyde in aerobic batch culture was much stronger than the inhibitory effect of cyanide per se.

\section{ATP generation and kinetics of respiratory inhibition in cyanide-treated non-growing cells}

As shown previously (Kalnenieks et al., 1993), nongrowing cells of $Z$. mobilis are able to perform oxidative phosphorylation with ethanol as a substrate. Here, aerobic ethanol consumption in whole cells was used as a convenient experimental model for qualitative estimation of the ATP-generating capacity of the cyanidesensitive respiration. We monitored the time course of ATP synthesis with ethanol as substrate in washed and concentrated cell suspensions obtained from aerobic exponential-phase cultures grown without cyanide addition (Fig. 6). The time course of intracellular ATP concentration in a control suspension and in cells preincubated (5-10 min) with $100 \mu \mathrm{M}$ cyanide is shown in the inset of Fig. 6(a). In cyanide-treated cells, intracellular ATP levels were raised within $10 \mathrm{~s}$ to a level about twofold higher than in control cells, but then declined. The columns in Fig. 6(a) represent the ATP levels measured at $10 \mathrm{~s}$ in cells pretreated with various cyanide concentrations, relative to that of control cells. These data strongly indicate that the Z. mobilis cyanide-sensitive respiratory pathway is an energynongenerating bypass, since its inhibition causes electron flux through a pathway with an overall increase in ATP synthesis.

Fig. 6(b) shows that cells preincubated with $100 \mu \mathrm{M}$ cyanide exhibited ethanol-supported oxygen uptake that was significantly lower than in control cells. Respiration rates measured over the first $1 \mathrm{~min}$ time interval were only $40 \%$ of the control (i.e. cyanide-untreated cells) and declined further thereafter.

\section{Cyanide sensitivity of whole cells and cytoplasmic membranes}

Whole cells and membrane preparations of Z. mobilis differed strikingly in their cyanide sensitivity (Fig. 6b). Even with $500 \mu \mathrm{M}$ cyanide, the initial inhibitory effect upon membrane respiration with $\mathrm{NADH}$ was much weaker than that of $100 \mu \mathrm{M}$ cyanide upon cells respiring ethanol. We hypothesized that some essential component of the cyanide-sensitive (rapidly inhibited) res- 

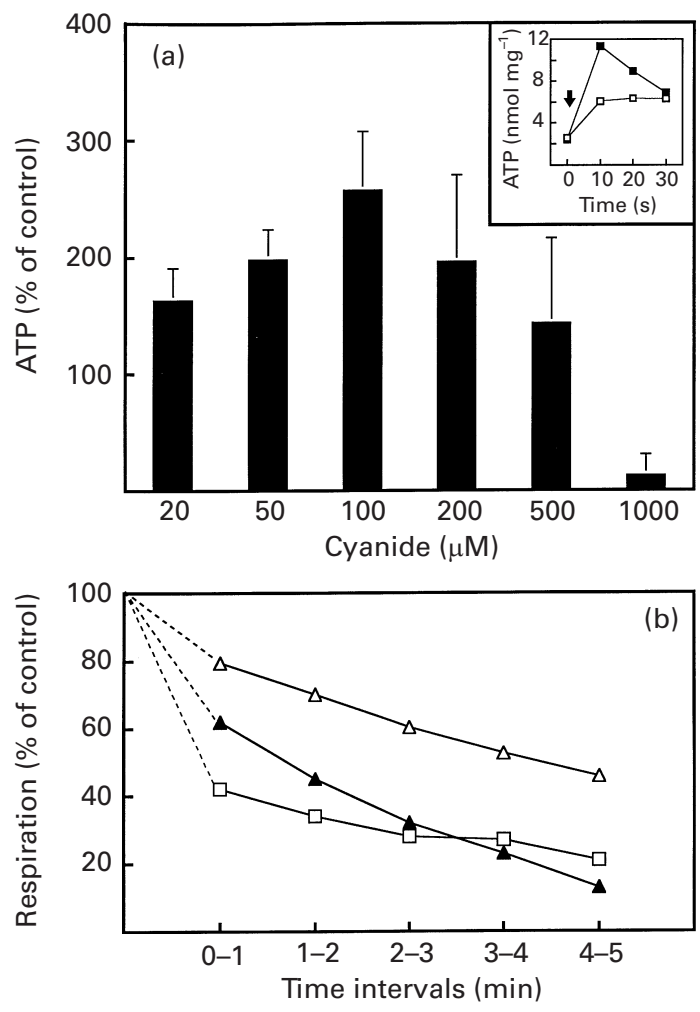

Fig. 6. Cyanide effects on ATP synthesis and respiration. (a) ATP synthesis in non-growing, cyanide-pretreated cells supplemented with ethanol. Bars show the intracellular levels of ATP reached $10 \mathrm{~s}$ after ethanol addition, relative to that in the control, taken as $100 \%$. Data represent the mean ( \pm SEM) of four independent experiments. Inset: time course of the rises in intracellular ATP levels after ethanol addition (marked by the arrow) in control cells $(\square)$ and in cells pretreated with $100 \mu \mathrm{M}$ cyanide ( $\boldsymbol{\square})$. (b) Time course of cyanide inhibition of respiration: in cell suspension pretreated with $100 \mu \mathrm{M}$ cyanide $(\square)$, in membranes pretreated with $100 \mu \mathrm{M}$ cyanide $(\triangle)$, in membranes pretreated with $500 \mu \mathrm{M}$ cyanide $(\boldsymbol{\Delta})$. Mean values of respiration rate (relative to the control) for each $1 \mathrm{~min}$ time interval are given.

piratory branch was either cytoplasmic, periplasmic or loosely bound to the cell membrane, and hence was easily lost in the process of membrane preparation. To test this, the supernatant fraction obtained after ultracentrifugation of the cell-free extract was concentrated 15 -fold by ultrafiltration (molecular mass cut-off, $10 \mathrm{kDa}$ ) and examined spectroscopically. To avoid too vigorous a disruption of membranes, a cell-free extract of aerobic exponentially growing cells for this experiment was prepared by gentle sonication, i.e. four periods of $30 \mathrm{~s}$ with $1 \mathrm{~min}$ intervals for cooling.

In Fig. 7, dithionite minus 'as prepared' difference spectra of membranes (A) and concentrated supernatant (B) are shown. Spectral features of a $b$-type haem were clearly present in the concentrated supernatant, namely an absorbance maximum at $559 \mathrm{~nm}$ in the $\alpha$-region, and a Soret band at $427.5 \mathrm{~nm}$. These signals are close to the respective absorbances in the membrane preparation.
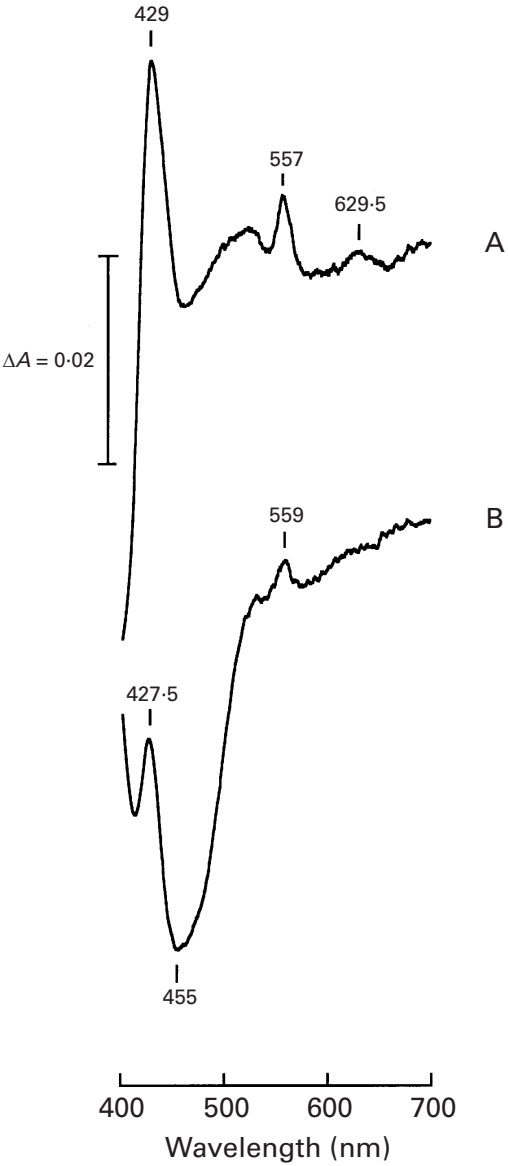

Fig. 7. Reduced minus 'as prepared' difference spectra of membranes (A) and concentrated supernatant fractions (B) obtained from cell-free extract of aerobically growing exponential-phase cells. Similar results were obtained in replicate scans. Protein concentrations in the cuvettes were $5 \mathrm{mg} \mathrm{ml}^{-1}$ in $A$ and $12 \mathrm{mg} \mathrm{ml}^{-1}$ in $B$.

However, the signal of cytochrome $d$ was evident only in the membrane difference spectrum. The prominent trough at $455 \mathrm{~nm}$ most probably corresponds to absorbance of an oxidized flavin moiety in the 'as prepared' concentrated supernatant sample. In contrast to what has been shown for $Z$. mobilis membrane preparations (Kalnenieks et al., 1998), as well as for the cytoplasmic flavohaemoglobin of E. coli (Ioannidis et al., 1992), haem $b$ in the $Z$. mobilis supernatant could not be reduced by NADH (not shown). This implies that a haem $b$-containing component in an intact cell might be loosely attached to the membrane and receive electrons from the electron transport chain, but not directly from NADH.

\section{DISCUSSION}

Z. mobilis, an aerotolerant, anaerobic ethanol-producing bacterium, has a surprisingly high respiratory capacity. Specific oxygen consumption rates reported for Z. mobilis membrane preparations (Bringer et al., 
1984; Kalnenieks et al., 1993) exceed those found in $E$. coli (e.g. Hertzberg \& Hinkle, 1974; Søballe \& Poole, 1998) three- to sixfold, and are comparable to the respiration in Azotobacter vinelandii (Kelly et al., 1990), probably the fastest respiring bacterium. Dissection of other bacterial respiratory pathways has benefited greatly from construction of directed mutants and their analysis, but most genetic approaches are currently unavailable or are difficult to use in studies of Z. mobilis electron-transport chains. Therefore, in the present study, we used cyanide to assess the overall role of respiration in the physiology and growth of this organism.

Remarkably, cyanide stimulated the growth of $Z$. mobilis, which otherwise during aerobic batch cultivation became inhibited by accumulation of acetaldehyde. In shaken flasks, a large part of the generated acetaldehyde did not evaporate from the culture fluid and at the end of cultivation its concentration exceeded $2 \mathrm{gl}^{-1}$. However, acetaldehyde accumulation in the medium seemed not to be the primary cause of growth inhibition in our experiments: we suggest that it was excess acetaldehyde generation inside the cells rather than its accumulation outside. This is supported by the observation that in a vigorously aerated continuous culture, in which acetaldehyde was efficiently gassed out, cyanide nevertheless stimulated growth. Apparently, in both modes of cultivation cyanide acted to prevent intracellular acetaldehyde generation/ accumulation, shown by the increase of $Y_{\mathrm{EtOH}}$ and slowdown of glucose consumption (see Table 1 and the scheme in Fig. 1).

An obvious conclusion from our data is that the high respiration rate in $Z$. mobilis is unnecessary for biomass growth: the rapid respiration does not supply any surplus energy for biosynthesis and growth, yet rapidly generates acetaldehyde (Fig. 1). The respiration might be also too rapid for the needs of respiratory protection, another vital physiological function of respiration in $Z$. mobilis proposed previously (Pankova et al., 1988). Presumably, the increase of the lag phase at higher cyanide concentrations might be explained in part by the respiratory protection hypothesis, the lag being due to full inhibition of respiration. As seen in Fig. 3, growth of the cyanide-treated cultures did not start while the specific respiration rate was close to zero. However, the cyanide-treated cultures then started exponential growth at a high specific rate when oxygen uptake rate was still well below half of that in the control culture (compare the growth and oxygen uptake rates between the fourth and seventh hour; Fig. 3). The inhibitory effect of cyanide on the glucose consumption rate (explicitly seen in the continuous culture; Table 1) also might contribute to the extension of the batch culture lag phase.

A cyanide-sensitive component of $\mathrm{NADH}$ oxidase activity, inhibited at around $20 \mu \mathrm{M}$ cyanide, has been reported previously in membranes of aerobically grown Z. mobilis (Toh \& Doelle, 1997), but no effect on membrane NADH oxidase activity could be seen at
$20 \mu \mathrm{M}$ cyanide in our experiments (not shown). This discrepancy might be explained by the different techniques of cell disruption used in each case. Toh \& Doelle (1997) disrupted cells with a French press, which might allow retention of a loosely membrane-bound component of the cyanide-sensitive branch. Sonication was used in our study. Preparation of cell-free extracts of glucose-grown E. coli by sonication can result in loss of dehydrogenases from the membrane into the 'soluble' fraction with consequent loss of energy-transducing function (e.g. ATP-dependent $\mathrm{NAD}^{+}$reduction) (Poole \& Haddock, 1974).

In the present whole-cell experiments, a large fraction of respiration was rapidly inhibited by low (e.g. $100 \mu \mathrm{M}$ ) cyanide concentrations (Fig. 6b). Its role in aerobic energetics of growing Z. mobilis cells is intriguing. Partial inhibition of cellular respiration by cyanide did not result in significant increase of biomass yield, contrary to what could be anticipated from our finding that the cyanide-sensitive pathway potentially was an energy-nongenerating bypass. However, respiratory inhibition by low cyanide concentrations was biphasic, with a rapid and a slower component (Fig. 6b). It might therefore be essential to distinguish between 'cyanidesensitive' and 'rapidly inhibited by cyanide' parts of $Z$. mobilis respiration. The former was inhibited during growth in the presence of low cyanide concentrations, while the latter was shown to be ATP-nongenerating in whole-cell experiments. The nature of this 'rapidly inhibited by cyanide', apparently energy-nongenerating, pathway of respiration in $Z$. mobilis cells and its possible relation to the haem $b$-containing compound found in the supernatant of cell-free extract needs to be established.

The physiological role of the rapid respiration in aerobically growing $Z$. mobilis cells is obviously other than ensuring biomass growth. It is tempting to think that the production of inhibitory metabolites, like acetaldehyde, is a competitive growth strategy of aerated Z. mobilis. Namely, Z. mobilis might prefer production of substances inhibitory for other bacteria at the expense of rapid growth of its own cell mass. Indeed, it is well established that $Z$. mobilis is inhibitory for other bacteria in interspecies conjugation experiments (Pappas et al., 1997), but this has been thought to be due to colicin production (Haffie et al., 1985). For anaerobic cultures, the competitive growth strategy of $Z$. mobilis might be based in part on the reported very high specific rates of ethanol production together with an ethanol tolerance exceeding that of many other micro-organisms (Viikari, 1988). A similar strategy for aerobic growth would then imply high, 'excessive' respiration rates, and would lead to the observed low growth yields and self-inhibition.

\section{ACKNOWLEDGEMENTS}

This work was supported by a grant to U.K. from the Volkswagen Foundation, Germany, and by a Fellowship to U.K. from the Royal Society and NATO. The authors are 
grateful to Dr S. Bringer-Meyer for helpful discussions and critical reading of the manuscript.

\section{REFERENCES}

Ashcroft, J. R. \& Haddock, B. A. (1975). Synthesis of alternative membrane-bound redox carriers during aerobic growth of Escherichia coli in the presence of potassium cyanide. Biochem J 148, 349-352.

Belaich, J. P. \& Senez, J. C. (1965). Influence of aeration and pantothenate on growth yields of Zymomonas mobilis. J Bacteriol 89, 1195-1200.

Bringer, S., Finn, R. K. \& Sahm, H. (1984). Effect of oxygen on the metabolism of Zymomonas mobilis. Arch Microbiol 139, 376-381.

Bringer-Meyer, S. \& Sahm, H. (1988). Acetoin and phenylacetylcarbinol formation by the pyruvate decarboxylases of Zymomonas mobilis and Saccharomyces carlsbergensis. Biocatalysis 1, 321-331.

Bringer-Meyer, S. \& Sahm, H. (1989). Junctions of catabolic and anabolic pathways in Zymomonas mobilis: phosphoenolpyruvate carboxylase and malic enzyme. Appl Microbiol Biotechnol 31, 529-536.

Eaves, D. J., Grove, J., Staudenmann, W., James, P., Poole, R. K., White, S. A., Griffiths, I. \& Cole, J. A. (1998). Involvement of products of the nrfEFG genes in the covalent attachment of haem $c$ to a novel cysteine-lysine motif in the cytochrome $c_{552}$ nitrite reductase from Escherichia coli. Mol Microbiol 28, 205-216.

Haffie, T. L., Louie, P. W. \& Khachaturians, G. G. (1985). Isolation of non-inhibitory strains of Zymomonas mobilis. Appl Environ Microbiol 49, 1007-1009.

Hertzberg, E. L \& Hinkle, P. C. (1974). Oxidative phosphorylation and proton translocation in membrane vesicles prepared from Escherichia coli. Biochem Biophys Res Commun 58, 178-184.

loannidis, N., Cooper, C. E. \& Poole, R. K. (1992). Spectroscopic studies on an oxygen binding haemoglobin-like flavohaemoprotein from Escherichia coli. Biochem J 288, 649-655.

Ishikawa, H., Nobayashi, H. \& Tanaka, H. (1990). Mechanism of fermentation performance of Zymomonas mobilis under oxygen supply in batch culture. J Ferment Bioeng 70, 34-40.

Jones, C. W. \& Doelle, H. W. (1991). Kinetic control of ethanol production by Zymomonas mobilis. Appl Microbiol Biotechnol 35, 4-9.

Kalnenieks, U., de Graaf, A. A., Bringer-Meyer, S. \& Sahm, H. (1993). Oxidative phosphorylation in Zymomonas mobilis. Arch Microbiol 160, 74-79.

Kalnenieks, U., Galinina, N., Irbe, I. \& Toma, M. (1995). Energy coupling sites in the electron transport chain of Zymomonas mobilis. FEMS Microbiol Lett 133, 99-104.

Kalnenieks, U., Galinina, N., Toma, M. \& Skards, I. (1996). Electron transport chain in aerobically cultivated Zymomonas mobilis. FEMS Microbiol Lett 143, 185-189.

Kalnenieks, U., Galinina, N., Bringer-Meyer, S. \& Poole, R. K. (1998). Membrane D-lactate oxidase in Zymomonas mobilis: evidence for a branched respiratory chain. FEMS Microbiol Lett 168, 91-97.

Kelly, M. J. S., Poole, R. K., Yates, M. G. \& Kennedy, C. (1990). Cloning and mutagenesis of genes encoding the cytochrome $b d$ terminal oxidase complex in Azotobacter vinelandii: mutants deficient in the cytochrome $d$ complex are unable to fix nitrogen in air. J Bacteriol 172, 6010-6019.

Kim, Y. J., Song, K. B. \& Rhee, S. K. (1995). A novel aerobic respiratory chain-linked NADH oxidase system in Zymomonas mobilis. J Bacteriol 177, 5176-5178.

Kita, K., Konishi, K. \& Anraku, Y. (1984). Terminal oxidases of Escherichia coli aerobic respiratory chain. II. Purification and properties of cytochrome $b_{558}-d$ complex from cells grown with limited oxygen and evidence of branched electron-carrying systems. J Biol Chem 259, 3375-3381.

Knowles, C. J. (1976). Microorganisms and cyanide. Bacteriol Rev 40, 652-680.

Markwell, M. A. K., Haas, S. M., Bieber, L. L. \& Talbert, N. E. (1978). A modification of the Lowry procedure to simplify protein determination in membrane and lipoprotein samples. Anal Biochem 87, 206-210.

Pankova, L. M., Shvinka, Yu. E., Beker, M. E. \& Slava, E. E. (1985). Effect of aeration on Zymomonas mobilis metabolism. Mikrobiologiya 54, 141-145.

Pankova, L. M., Shvinka, J. E. \& Beker, M. J. (1988). Regulation of intracellular $\mathrm{H}^{+}$balance in Zymomonas mobilis 113 during the shift from anaerobic to aerobic conditions. Appl Microbiol Biotechnol 28, 583-588.

Pappas, K.-M., Galani, I. \& Typas, M. A. (1997). Transposon mutagenesis and strain construction in Zymomonas mobilis. J Appl Microbiol 82, 379-388.

Poole, R. K (2000). Aerobic respiration: oxidases and globins. In Encyclopaedia of Microbiology, 2nd edn, vol. 1, pp. 53-68. Edited by J. Lederberg and others. San Diego: Academic Press.

Poole, R. K. \& Cook, G. M. (2000). Redundancy of aerobic respiratory chains in bacteria? Routes, reasons and regulation. Adv Microb Physiol 43 (in press).

Poole, R. K. \& Haddock, B. A. (1974). Energy-linked reduction of nicotinamide-adenine dinucleotide in membranes derived from normal and various respiratory-deficient mutant strains of Escherichia coli K12. Biochem J 144, 77-85.

Søballe, B. \& Poole, R. K. (1998). Requirement for ubiquinone downstream of cytochrome(s) $b$ in the oxygen-terminated respiratory chains of Escherichia coli K-12 revealed using a null mutant allele of ubiCA. Microbiology 144, 361-373.

Stanley, G. A., Hobley, T. J. \& Pamment, N. B. (1997). Effect of acetaldehyde on Saccharomyces cerevisiae and Zymomonas mobilis subjected to environmental shocks. Biotechnol Bioeng 53, 71-78.

Toh, H. \& Doelle, H. (1997). Changes in the growth and enzyme level of Zymomonas mobilis under oxygen-limited conditions at low glucose concentration. Arch Microbiol 168, 46-52.

Viikari, L. (1988). Carbohydrate metabolism in Zymomonas. Crit Rev Biotechnol 7, 237-261.

Wecker, M. S. A. \& Zall, R. R. (1987). Production of acetaldehyde by Zymomonas mobilis. Appl Environ Microbiol 53, 2815-2820.

Zikmanis, P., Kruce, R. \& Auzina, L. (1997). An elevation of the molar growth yield of Zymomonas mobilis during aerobic exponential growth. Arch Microbiol 167, 167-171.

Received 3 February 2000; accepted 8 March 2000. 